\title{
Recruitment and Retention
}

Strategies for Environmental

Exposure Studies: Lessons

from the Detroit Exposure and

Aerosol Research Study

Michael J. Phillips, Charles E. Rodes,

Jonathan W. Thornburg, Roy W. Whitmore,

Alan F. Vette, and Ronald W. Williams

November 2010 


\section{About the Authors}

Michael J. Phillips, BS, is a health research analyst at RTI International.

Charles E. Rodes, PhD, is a Senior Fellow and aerosol scientist at RTI International.

Jonathan W. Thornburg, PhD,

is a senior aerosol scientist at RTI

International.

Roy W. Whitmore, $\mathrm{PhD}$, is a senior statistician at RTI International.

Alan F. Vette, PhD, is a physical scientist at the US Environmental Protection Agency in Research

Triangle Park, North Carolina.

Ronald W. Williams, BS, is a

supervisory physical scientist at the US Environmental Protection Agency.
RTI Press publication MR-0021-1011

This PDF document was made available from www.rti.org as a public service of RTI International. More information about RTI Press can be found at http://www.rti.org/rtipress.

RTI International is an independent, nonprofit research organization dedicated to improving the human condition by turning knowledge into practice. The RTI Press mission is to disseminate information about RTI research, analytic tools, and technical expertise to a national and international audience. RTI Press publications are peer-reviewed by at least two independent substantive experts and one or more Press editors.

\section{Suggested Citation}

Phillips, M. J., Rodes, C. E., Thornburg, J. W., Whitmore, R. W., Vette, A. F., and Williams, R. W. (2010). Recruitment and Retention Strategies for Environmental Exposure Studies: Lessons from the Detroit Exposure and Aerosol Research Study. RTI Press publication No. MR-0021-1011. Research Triangle Park, NC: RTI Press. Retrieved [date] from http://www.rti.org/rtipress.

C2010 Research Triangle Institute. RTI International is a trade name of Research Triangle Institute.

All rights reserved. Please note that this document is copyrighted and credit must be provided to the authors and source of the document when you quote from it. You must not sell the document or make a profit from reproducing it.

doi:10.3768/rtipress.2010.mr.0021.1011

www.rti.org/rtipress 


\section{Recruitment and Retention Strategies for Environmental Exposure Studies: Lessons from the Detroit Exposure and Aerosol Research Study}

\author{
Michael J. Phillips, Charles E. Rodes, \\ Jonathan W. Thornburg, Roy W. Whitmore, \\ Alan F. Vette, and Ronald W. Williams
}

\begin{tabular}{lc} 
Contents & \\
Introduction & 2 \\
Methods & 2 \\
$\quad$ Sample Design & 3 \\
$\quad$ Eligibility Criteria & 3 \\
The Study Area & 3 \\
Recruitment & 5 \\
Community Action Groups & 6 \\
Calculating Recruitment & \\
$\quad$ Response Rates & 7 \\
Enrollment & 7 \\
Retention & 7 \\
Protocol Compliance & 8 \\
Results & 8 \\
Recruitment & 8 \\
Enrollment & 11 \\
Retention & 13 \\
Protocol Compliance & 12 \\
Discussion & 13 \\
Recruitment & 13 \\
Enrollment & 13 \\
Retention & 13 \\
Protocol Compliance & \\
References & \\
Acknory & 13 \\
\hline
\end{tabular}

Acknowledgments Inside back cover

six geographically defined areas in the Detroit (Wayne County), Michigan, area used as study locations are ethnically diverse; the majority of the residents are African American or Hispanic. Each summer and winter season, the study solicited 40 adult nonsmoking study participants from these predefined areas. Participants were asked to allow home visits each morning for a week, to wear a personal exposure monitoring vest, and to complete an activity diary and follow-up questionnaire each day. Community action groups, recruitment staff, and environmental technicians coordinated the recruitment and environmental sampling activities. Although the study had an overall response rate of 19 percent, recruitment goals were met nearly every season in each geographic area. Over-recruitment was necessary to replace dropouts. Recruitment staff used face-to-face household recruitment to enroll 136 study participants. Among participants, 73 percent participated in two seasons. Details about the recruitment techniques used in exposure studies, as well as the lessons learned, rarely appear in the literature. This report delineates the lessons from the DEARS that may be beneficial to other researchers using similar study designs in lowincome, ethnically diverse urban areas. 


\section{Introduction}

Longitudinal research requires effective recruitment and retention techniques. These components are particularly important for personal exposure studies, which potential participants may perceive as intrusive and burdensome. In addition, the recruitment and retention of cohorts in lower income, ethnically diverse, inner-city populations can present obstacles. ${ }^{1-3}$ For example, challenges may include a lack of working telephones, English-language barriers for prospective and enrolled participants, participants whose addresses change frequently, and a mistrust of researchers. ${ }^{1,4,5}$ However, details about the recruitment techniques used in these types of studies, as well as the lessons learned, rarely appear in the literature.

Typically, studies requiring a substantial time commitment or involving burdensome procedures have lower response rates. ${ }^{1,6}$ In recent years, however, the rate of nonparticipation in epidemiological studies has been increasing, primarily because of refusals and difficulty finding eligible study participants. ${ }^{7}$ These issues can pose logistical, scheduling, and communication problems during study recruitment and exposure phases, as well as in longitudinal follow-up retention periods.

Researchers often need to modify recruitment or retention approaches to maximize participation. For example, Dugbatey and colleagues had difficulty reaching enrolled participants for follow-up (e.g., no telephone in the home, frequent address changes, cancelled appointments, no-shows). Additional home visits were necessary to meet with the participants to alleviate these problems. ${ }^{8}$ Chuang et al. had a large sample in their study but used rigid eligibility criteria, so alternative methods (e.g., household screening, telephone recruitment, mailings, placing study materials in public locations) were used to reach the target population. ${ }^{9}$ RIOPA (Relationships of Indoor, Outdoor, and Personal Air) staff identified target areas close to ambient sources and used several community outreach techniques-such as interviews with local newspapers, interviews with radio and television stations, presentations at community centers and churches, and word of mouth - to recruit more participants. ${ }^{10}$

Another approach to counter this trend is the involvement of community action groups and other outreach organizations that support local minority groups to enhance participation in clinical, epidemiological, and environmental studies. ${ }^{11-13}$ Such local organizations, often with the same goals as the study or intervention, can facilitate recruitment in difficult environments. For example, a children's health center funded by the National Institute of Environmental Health Sciences (NIEHS) and the US Environmental Protection Agency (EPA), based in Detroit, Michigan, conducted a study of the relationship between children's asthma and levels of particulate matter and ozone. The study's steering committee, made up of several public health and community-based partners, worked closely with Community Action Against Asthma (CAAA), a community-based organization, to address the original research questions; hire and train data collection and intervention staff; design survey instruments; plan recruitment, enrollment, and retention efforts; and interpret, disseminate, and translate the research findings. ${ }^{14}$

This report describes the recruitment and retention efforts used for the Detroit Exposure and Aerosol Research Study (DEARS), a repeated-measure human exposure study. The DEARS was conducted by the EPA and supported by RTI International. The design, goals, and field implementation of this study have been described elsewhere. ${ }^{15,16}$

\section{Methods}

The DEARS was a multiseason air pollutant exposure study conducted during the summer and winter seasons (six consecutive seasons) between 2004 and 2007. Data were collected consistently during each 7-week July-August summer season and each 7-week late January-March winter season. The DEARS field technicians measured indoor, outdoor, and personal exposure levels of air toxics and particulate matter. ${ }^{16}$ The overall recruitment goal was to enroll a total of 40 study participants in each summer season of 
exposure sampling and then re-enroll the same study participants to repeat the activities in the subsequent winter season. To meet its study design objectives, the DEARS needed a total of 120 participants. Recruitment complicated the study design because nine participants were needed specifically from each predefined area, regardless of the population size, for each sampling season to provide the desired spatial representation in Wayne County, Michigan. ${ }^{15}$

\section{Sample Design}

Address lists for each area-purchased from Marketing Systems Group (Fort Washington, Pennsylvania), a marketing list vendor-included name, address, and telephone number, if available. Addresses were sent to Tele Atlas (Lebanon, New Hampshire) for geocoding. Once RTI obtained the geocoordinates, a geographic information specialist mapped them to identify the sample addresses in each target area.

To achieve a random participant sample, we selected several stratified systematic samples (cluster samples) from an address list sampling frame for each enumeration monitoring area (EMA). Before selecting the systematic samples, we sorted the frame for each EMA by the 2000 Census block group and record ID, which ensured that each systematic (cluster) sample was geographically dispersed across the EMA. This sampling strategy was designed to ensure geographic representativeness and to protect against selection bias. Given the expected high rates of nonresponse, ineligibility, and vacancies, we contacted homes from several systematic clusters in each EMA to facilitate estimation of sampling variance based on variability between clusters. Fieldwork began with the first randomly selected sample cluster for each EMA. We randomly ordered addresses within each sample cluster so that recruiters could work as far into the list as necessary to obtain the needed respondents. When necessary, we added more sample homes from backup census tracts.

\section{Eligibility Criteria}

Eligible participants had to be aged 18 or older, live in one of the defined EMAs, be a nonsmoker, agree not to allow any smoking in their home during the sampling period, be able to walk unassisted, be able to answer questions and complete surveys in English or Spanish (the questions and surveys used during the DEARS are available from www.epa.gov/DEARS), plan to live in the same single-family detached house for the next 9 months, and be available for 7 consecutive days of home visits, including a "setup day" followed by 5 days of environmental monitoring and a "takedown day." During the monitoring period, participants needed to be available for a 1-hour home visit at the same time each morning between 6:30 a.m. and 11:30 a.m.

\section{The Study Area}

The EPA chose the Wayne County area, which includes all of Detroit, as the study location because of the level of ambient air pollution and ideal factors that made it the best location for the exposure study design, including the number of pollutant sources, air monitoring network already in place, and support from the state and local community groups. Industry and heavy traffic (e.g., cars and diesel trucks) are the primary sources of air pollution in this urban area. The investigators selected areas of Wayne County adjacent to industrial and traffic sources to facilitate the comparison of indoor, outdoor, and personal measurements of air pollutants.

We selected six pre-established EMAs for random participant recruitment because of their proximity to industrial, mobile, or diesel sources of air pollution (Figure 1). Note that EMA 2 does not appear in the figure; it was not included in the study because the area is located near a major roadway and closely resembles other EMAs. EMA 7 (not shown in Figure 1) is located approximately 30 miles west of Detroit and was used primarily to collect background air pollutant data.

Table 1 summarizes census tracts in each EMA selected to satisfy the DEARS study design. We selected one census tract per EMA for recruitment, except in EMA 6. Participant recruitment in EMA 6 required eight census tracts over the six seasons to obtain the desired number of participants (see size of EMA 6 in Figure 1). 


\section{Figure 1. DEARS enumeration monitoring areas (EMAs) in Detroit, Michigan}

DEARS $=$ Detroit Exposure and Aerosol Research Study

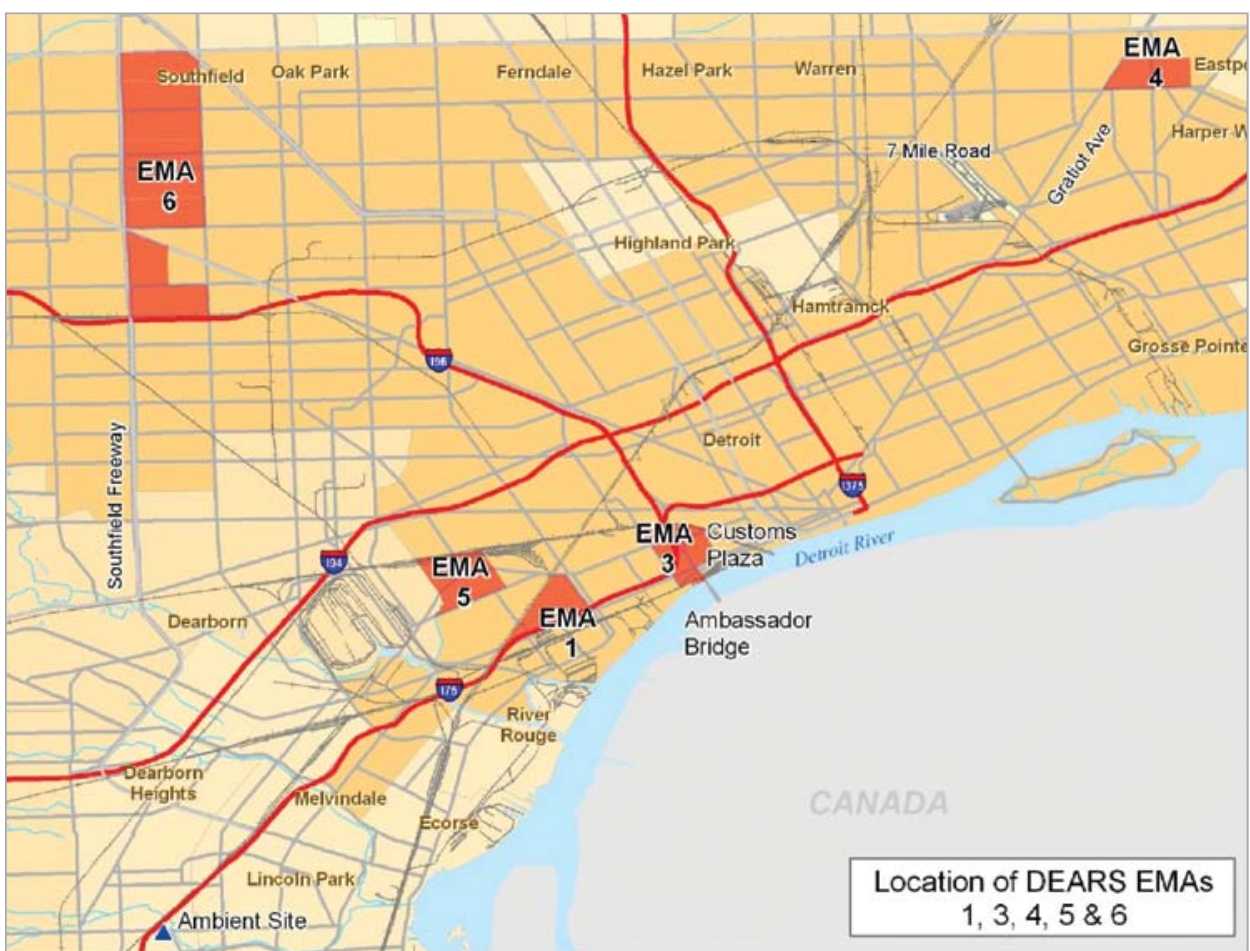

Table 1. Census tracts selected for recruitment in each EMA for the DEARS

\begin{tabular}{|c|c|c|c|c|c|c|}
\hline EMA & $\begin{array}{l}\text { Census } \\
\text { Tract(s) }\end{array}$ & $\begin{array}{c}\text { Population } \\
(\%)^{\mathrm{a}}\end{array}$ & $\begin{array}{c}\text { Percentage } \\
\text { Minority }\end{array}$ & $\begin{array}{l}\text { Median } \\
\text { Household } \\
\text { Incomec }^{c}\end{array}$ & $\begin{array}{c}\text { Area, mi2 } \\
(\%)^{d}\end{array}$ & Description \\
\hline 1 & 5238 & $\begin{array}{l}5,543 \\
(0.27 \%)\end{array}$ & 69.2 & $\$ 30,134$ & $\begin{array}{c}0.5 \\
(0.08 \%)\end{array}$ & More than $200 \mathrm{~m}$ from Interstate 75. \\
\hline 3 & 5211 & $\begin{array}{l}2,012 \\
(0.10 \%)\end{array}$ & 86.4 & $\$ 35,658$ & $\begin{array}{c}0.4 \\
(0.07 \%)\end{array}$ & Within $200 \mathrm{~m}$ of Customs Plaza, when possible. \\
\hline 4 & 5003 & $\begin{array}{c}4,606 \\
(0.22 \%)\end{array}$ & 85.7 & $\$ 32,540$ & $\begin{array}{c}0.5 \\
(0.08 \%)\end{array}$ & $\begin{array}{l}\text { Within } 200 \mathrm{~m} \text { of Gratiot Avenue for Seasons } 1 \\
\text { and 2. Seasons } 3 \text { through 6-further than } 200 \mathrm{~m} \\
\text { from Gratiot. }\end{array}$ \\
\hline 5 & 5241 & $\begin{array}{c}4,827 \\
(0.23 \%)\end{array}$ & 70.0 & $\$ 29,688$ & $\begin{array}{c}0.7 \\
(0.11 \%)\end{array}$ & More than $200 \mathrm{~m}$ from Interstate 75 and railroad. \\
\hline 6 & $\begin{array}{l}5425,5426,5404,5421 \\
5422,5401,5402,5403\end{array}$ & $\begin{array}{l}33,838 \\
(1.64 \%)\end{array}$ & 97.8 & $\$ 43,025$ & $\begin{array}{c}3.9 \\
(0.64 \%)\end{array}$ & Within 200 m of M39-Southfield Freeway. \\
\hline 7 & 5870 & $\begin{array}{l}4,002 \\
(0.19 \%)\end{array}$ & 13.7 & $\$ 56,071$ & $\begin{array}{c}2.6 \\
(0.42 \%)\end{array}$ & $\begin{array}{l}\text { More than } 200 \mathrm{~m} \text { from major roadway. Single, } \\
\text { outdoor-only residence for Seasons } 3 \text { through } 6 \text {. }\end{array}$ \\
\hline \multicolumn{2}{|c|}{ All EMAs } & $\begin{array}{l}54,828 \\
(2.67 \%)\end{array}$ & 84.9 & $\$ 40,638$ & $\begin{array}{c}8.61 \\
(1.40 \%)\end{array}$ & \\
\hline \multicolumn{2}{|c|}{ Wayne County, Michigan } & $2,061,162$ & 48.3 & $\$ 40,776$ & 614 & \\
\hline
\end{tabular}

DEARS $=$ Detroit Exposure and Aerosol Research Study $;$ EMA $=$ enumeration monitoring area

a Total population in Census tract per 2000 Census data. Percentages in parentheses represent the Census tract's population divided by Wayne County's population.

b Minority is the percentage of the Census tract's population that is considered minority (primarily African American or Hispanic).

c Median household income represents the median household income of the Census tract.

d Area, $\mathrm{mi}^{2}$ is area in square miles of the Census tract, and the percentage is the size of the Census tract compared to the size of the Census tract in Wayne County. Note: 2000 U.S. Census data were used to summarize the demographic characteristics in the table. The EMA percentage relative to all of Wayne County, Michigan, is presented for the population and land area categories. 
Table 1 also presents the demographics of the census tracts selected for recruitment, including the population in each census tract, the percentage of the minority population, the median income, and the size of the area in square miles. Most minority residents in each census tract are either African American or Hispanic. All EMAs, except EMA 7, had a high percentage of minority populations, with EMA 6 approaching 98 percent.

\section{Recruitment}

Recruitment involved identifying, contacting, and screening residents of the EMAs to explain the purpose of the DEARS and attempt to obtain their verbal consent to participate. Recruitment for the 40 study participants began each year approximately 30 days before the start of exposure sampling and continued until enough recruits were identified to fill the 7 -week schedule for the sampling season. The sample design required one or two study participants to be sampled in each EMA during each week. Recruitment procedures were similar throughout the study. Figure 2 presents a flowchart of the sequence of recruitment and enrollment activities.

Before carrying out the door-to-door recruitment effort, we mailed lead letters and study brochures to randomly selected household units in each EMA. Recruiters visited each household on the address list up to three times on different days and at different times to screen the residents. If the respondent was successfully screened and expressed interest in participating, recruiters described the study in more detail. Information about eligible recruits who wanted to participate was shared with the recruitment manager, who helped prepare the weekly sampling schedule.

Recruiters addressed issues of participant burden, including the time requirement, the equipment being set up in the residence and outside in the backyard, the personal exposure measurements, and various other requirements (e.g., time-activity diary). In addition, recruiters shared the Frequently Asked Questions (FAQ) document and pictures of the study equipment with respondents during the recruitment visit. A study recruitment video called "Breathing
Figure 2. Recruitment and enrollment sequence

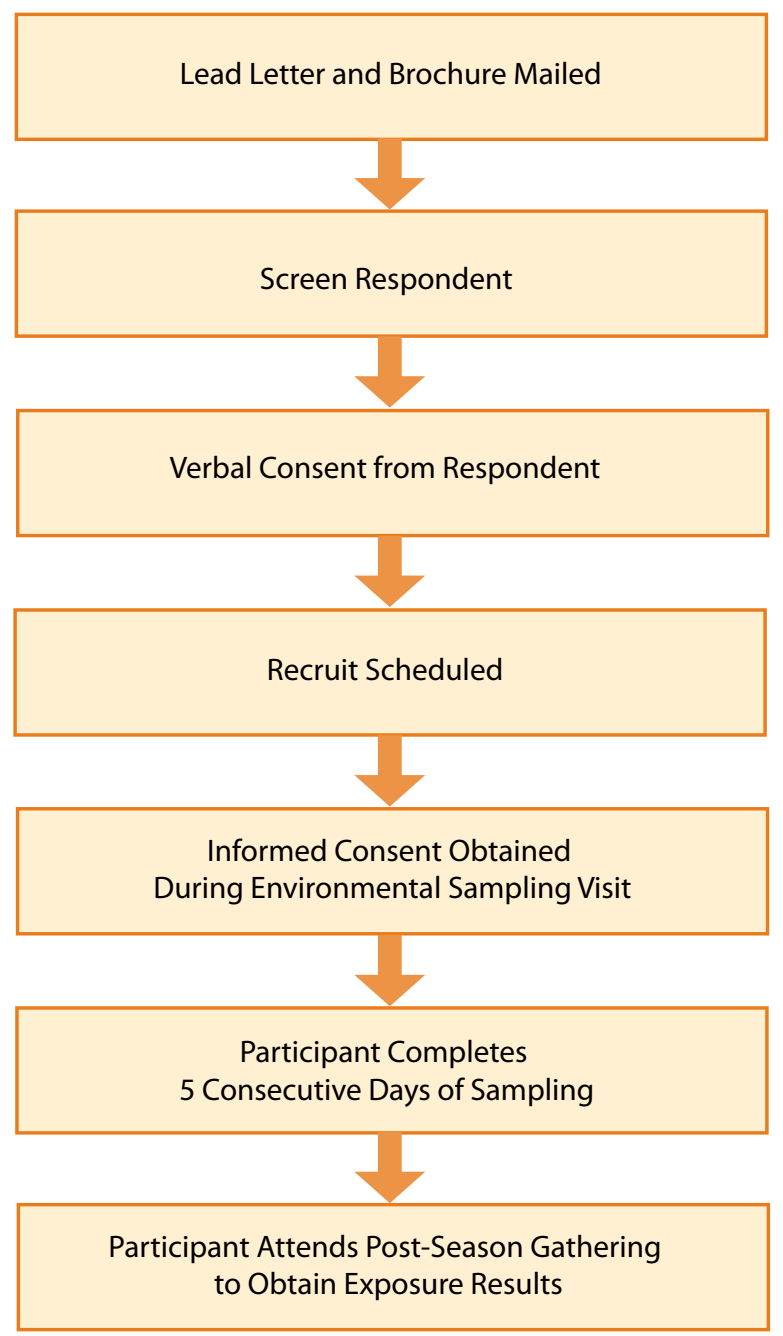

Right in Detroit" also was made available to potential participants. All recruitment materials were approved by RTI's Institutional Review Board (IRB) and the EPA's Office of Human Subjects Research, and they were available in English and Spanish versions. The brochure and the FAQ document included pictures of people wearing the personal exposure monitoring vest and the cadre of indoor and outdoor monitors that would be located in a selected room in the residence and in the backyard (Figure 3). Although optimized by numerous redesigns, the vest posed a modest physical burden that we needed to explain to participants in advance. As shown in Figure 3a, the vest incorporates a range of active and passive exposure sampling components and is worn over the participant's clothing during waking hours for 5 consecutive days. 
Although it had a small footprint (1 square foot), the indoor sampling platform (Figure $3 \mathrm{~b}$ ) proved somewhat difficult to deploy in smaller homes. Small rooms crowded with furniture made it difficult to place the platform in a location that complied with study protocols. This platform needed to be placed in the room of greatest participant activity, but also more than $1 \mathrm{~m}$ from the wall, windows, and doors.

The outdoor sampling platform (Figure 3c) required space in the sometimes small or congested backyard to avoid obstruction of the sample inlets. In addition, unfriendly dogs sometimes posed a challenge for the field technicians during home visits.

Local community action group members were hired as the DEARS recruiters. Every reasonable attempt was made to match the race/ethnicity of the recruiter with the race/ethnicity of the EMA residents. Recruiters were hired based on their relevant experience, and nearly all of the recruiters had experience performing door-to-door recruitment.

\section{Figure 3. Sample collection platforms deployed during the DEARS}

DEARS $=$ Detroit Exposure and Aerosol Research Study
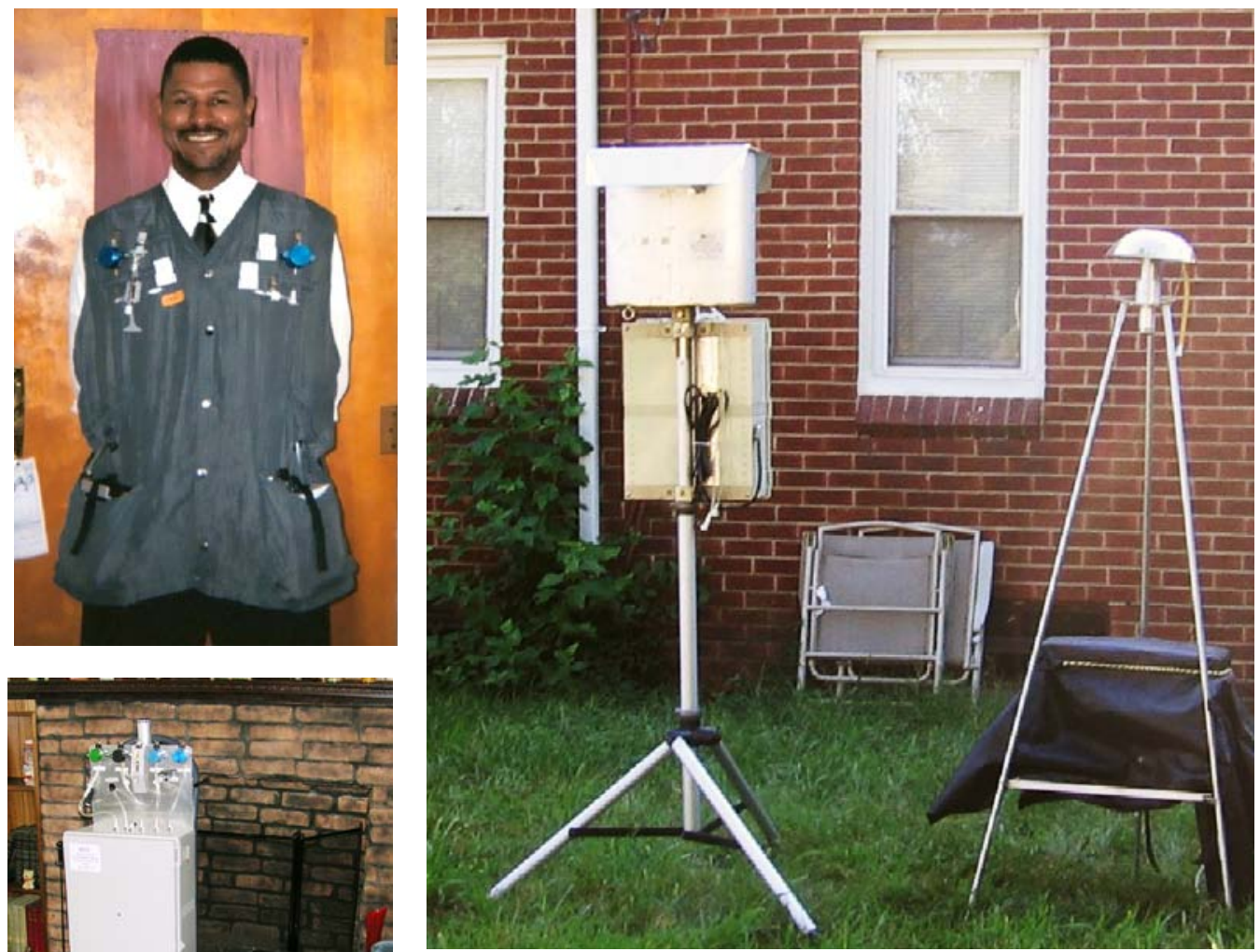

a) Left top: Personal exposure monitoring vest, b) Left bottom: Indoor sampling platform, and c) Above: Outdoor sampling platform.
Each recruiter was provided with a recruitment manual, trained, and shown the monitoring equipment deployed by the technicians. Typically, one recruiter was assigned to one EMA. During each season, one on-site recruiter led the task and oversaw the team of recruiters.

One recruiter was bilingual and visited the Hispanic households. This recruiter assisted the nonbilingual recruitment staff and served as a translator for the field technicians by scheduling home visits and accompanying the technicians as the field equipment was deployed.

\section{Community Action Groups}

During initial planning for the DEARS, staff from the EPA, the Michigan Department of Environmental Quality, CAAA, and RTI met to discuss the study design. CAAA and the Michigan Department of Environmental Quality raised concerns about the exposure areas of interest, recruitment barriers, 
participant burden, and sharing of the results with the study participants. An additional concern was how receptive the multiethnic neighborhoods would be to door-to-door recruitment efforts. These discussions enhanced recruitment planning by enabling the research team to learn more about the cultural differences, potential barriers, and needs and concerns of the community.

After the first year of the study, members of the Arab Community Center for Economic and Social Services (ACCESS), the Community Health and Social Services Center (CHASS), and CAAA were invited to meet to discuss recruitment in Arabic, African American, and Hispanic neighborhoods of Detroit. Although Arabic residents were never approached to participate in the DEARS, because their neighborhoods were not included in the study design, this meeting was also beneficial to discuss the culture, needs, and concerns of the different communities and to identify recruitment strategies.

\section{Calculating Recruitment Response Rates}

Recruitment success was quantified by calculating the overall recruitment response rate (ORRR). The formulas are part of a two-stage complex design, as described by the American Association of Public Opinion Research. ${ }^{17}$ The ORRR is the product of the screening stage response rate (SSRR) and the recruitment stage response rate (RSRR). Stage I of the recruitment process, the SSRR, is the percentage of eligible households that completed the household screener. The numerator is the number of households that completed the screening. The denominator is the number of eligible households, including the nonresponding households. Ineligible households do not influence this response rate equation. Stage II, the RSRR, is the number of respondents divided by the number of eligible households. We used these formulas to calculate the response rates that appear in Tables 2 and 3 (located in the Results section).

\section{Enrollment}

Recruiters immediately shared information about new recruits with the recruitment manager who contacted the recruits again and inquired about their availability for a week of home visits. An updated sampling schedule for the next week was sent to the technicians a few days in advance. The schedule also included special-needs information about participants, such as unusual work schedules, large or possibly aggressive pets, or the presence of small children. Informed consent was obtained during the first home visit with the technicians.

The incentive levels for the DEARS resulted from a careful review of burden imposed on participants and the prior incentive levels applied for similar burdens, as described in the IRB applications. Study participants received the following compensation: $\$ 20$ per day plus $\$ 5$ per day (for electricity) during the summer season and $\$ 30$ per day plus $\$ 5$ per day (for electricity) during the winter season. The increased incentive for the winter season was intended to encourage participants to continue the study. They also received a $\$ 50$ gift certificate upon completing the first day of sampling in each season. Participants were compensated for 5 days of sampling each season and not compensated for the setup day and takedown day. If they participated fully in both seasons, participants received $\$ 300$ total plus two $\$ 50$ gift certificates.

\section{Retention}

Successful retention for the DEARS - the ability to maintain participation for the longitudinal component of the study-meant continued participation in the subsequent winter season following participation in the first summer season. Between-season retention efforts included meetings to inform the participants about key individual pollutant-level findings, "touch base" telephone calls, a retention encouragement letter, and a prewinter season appointment letter that included a calendar to allow the participant the flexibility to choose the most accommodating study week.

To offer a recruitment and retention benefit, the EPA principal investigator provided all participants with a written summary of selected personalized findings. In addition, a postseason results meeting gave participants an opportunity to meet with the EPA principal investigator and ask questions about the study's progress and their selected personalized findings. 


\section{Protocol Compliance}

The field technicians closely monitored participants' compliance with the study protocol on a daily basis, including if they wore the vest or allowed smoking in the residence. Participant vest compliance was monitored by a capacitance sensor and a thermocouple built into the RTI personal exposure monitoring system. The capacitance sensor measured two-dimensional movement of the exposure monitoring system. ${ }^{18}$ The temperature recorded by the thermocouple provided a secondary indication that the participant wore the vest. Technicians used the movement and temperature data to assess the previous day's compliance during their visit the following morning.

Tobacco smoke compliance was monitored by optical transmittance analysis of the $\mathrm{PM}_{2.5}$ filters. ${ }^{19}$ Filters exposed to environmental tobacco smoke (ETS) exhibit a distinct yellow discoloration that is proportional to the amount of ETS. An ETS concentration greater than $1.5 \mu \mathrm{g} / \mathrm{m}^{3}$ violated the DEARS protocol. Technicians reviewed protocol compliance with the participant on a daily basis. If poor compliance was observed, technicians urged participants to comply with study protocols by fostering a friendly relationship, reiterating the societal benefits of the study, and reminding the participant of the maximum monetary compensation. Following each season, the RTI team thoroughly reviewed ways to improve study compliance.

\section{Results}

\section{Recruitment}

Tables 2 and 3 summarize the recruitment statistics and response rates for the DEARS by EMA and by season, respectively. The results are presented by categories and subcategories based on the final disposition of each residence.

Ineligible residences included the following subcategories: not a residential address, unable to locate address, and multifamily dwelling. The multifamily dwelling subcategory was deemed ineligible if the housing unit shared the same heating system with another housing unit. A relatively large number of all housing units were ineligible residences (168 of 1,702, or 10 percent). Table 2 illustrates the percentage of ineligible residences in each EMA; for example, EMA 3 had a total of 28 (18 percent) ineligible residences of the total of 158 residences visited (see row for Total-All Categories).

In addition, Table 2 indicates that nonresponding households comprise a majority of the total households visited (59 percent). Many of these households were classified as nonresponding for two main reasons: no one at the residence (29 percent) and refused screener (29 percent). Ineligible households consisted of households having respondents who did not pass the screener because a smoker lived in the household, a language barrier existed, or the respondent was physically or mentally incapable. Households with smokers (180) made up a substantial number of the total number of ineligible households (235). Nonresponding persons included individuals who refused to participate after screening and those in the "other" category, which included individuals who may have participated but could not because of their work schedule or for other personal reasons. Finally, some of the individuals recruited who verbally agreed to participate in the DEARS ultimately never provided written consent.

The number of individuals recruited in each EMA differs (see Recruits row in Table 2), which reflects the study design (inclusion or exclusion of specific EMAs in each season). For example, EMAs 1, 4, and 6 had the greatest number of individuals recruited because participants were needed from those EMAs for each season of the DEARS. EMA 2 was never included, and participants in EMA 3 were sampled during Seasons 1 through 4, but only outdoor measurements were needed during Seasons 5 and 6. Participants from EMA 7, the background area, were sampled in Seasons 1 and 2 but not in the later seasons.

Table 2 also indicates the response rates. The SSRRs ranged from 15 percent in EMA 5 to 52 percent in EMA 7. The RSRRs were higher and ranged from 47 to 64 percent. The product of the two response rates was the ORRR in each EMA, which ranged from 10 percent in EMA 5 to 30 percent in EMA 7. The ORRR across all seasons was 19 percent. 
Table 2. Cohort recruitment details in each EMA for the DEARS, by categories and subcategories

\begin{tabular}{|c|c|c|c|c|c|c|c|c|}
\hline Category & Subcategory & EMA 1 & EMA 3 & EMA 4 & EMA 5 & EMA 6 & EMA 7 & Total \\
\hline \multirow{5}{*}{$\begin{array}{l}\text { Ineligible } \\
\text { Residences }\end{array}$} & $\begin{array}{l}\text { Not a residential } \\
\text { address }\end{array}$ & 4 & 2 & 1 & 13 & 2 & 0 & 22 \\
\hline & $\begin{array}{l}\text { Unable to locate } \\
\text { address }\end{array}$ & 6 & 13 & 1 & 2 & 3 & 2 & 27 \\
\hline & Vacant & 14 & 2 & 34 & 18 & 8 & 0 & 76 \\
\hline & Multifamily dwelling & 16 & 11 & 9 & 0 & 6 & 1 & 43 \\
\hline & Category Total & $\begin{array}{c}40 \\
(9 \%)\end{array}$ & $\begin{array}{c}28 \\
(18 \%)\end{array}$ & $\begin{array}{c}45 \\
(12 \%)\end{array}$ & $\begin{array}{c}33 \\
(10 \%)\end{array}$ & $\begin{array}{c}19 \\
(5 \%)\end{array}$ & $\begin{array}{c}3 \\
(5 \%)\end{array}$ & $\begin{array}{c}168 \\
(10 \%)\end{array}$ \\
\hline \multirow{4}{*}{$\begin{array}{l}\text { Nonresponding } \\
\text { Households }\end{array}$} & No one at residence & 107 & 47 & 76 & 108 & 152 & 3 & 493 \\
\hline & Access denied & 8 & 0 & 4 & 4 & 5 & 0 & 21 \\
\hline & Refused screener & 104 & 29 & 106 & 134 & 99 & 22 & 494 \\
\hline & Category Total & $\begin{array}{c}219 \\
(51 \%)\end{array}$ & $\begin{array}{c}76 \\
(49 \%)\end{array}$ & $\begin{array}{c}186 \\
(51 \%)\end{array}$ & $\begin{array}{c}246 \\
(76 \%)\end{array}$ & $\begin{array}{c}256 \\
(68 \%)\end{array}$ & $\begin{array}{c}25 \\
(45 \%)\end{array}$ & $\begin{array}{l}1,008 \\
(59 \%)\end{array}$ \\
\hline \multirow{4}{*}{$\begin{array}{l}\text { Ineligible } \\
\text { Households }\end{array}$} & Smoker in household & 51 & 14 & 52 & 15 & 40 & 8 & 180 \\
\hline & $\begin{array}{l}\text { Language barrier; } \\
\text { other }\end{array}$ & 27 & 8 & 1 & 0 & 0 & 0 & 36 \\
\hline & $\begin{array}{l}\text { Physically/mentally } \\
\text { incapable }\end{array}$ & 12 & 1 & 4 & 2 & 0 & 0 & 19 \\
\hline & Category Total & $\begin{array}{c}90 \\
(21 \%)\end{array}$ & $\begin{array}{c}23 \\
(15 \%)\end{array}$ & $\begin{array}{c}57 \\
(16 \%)\end{array}$ & $\begin{array}{c}17 \\
(5 \%)\end{array}$ & $\begin{array}{c}40 \\
(11 \%)\end{array}$ & $\begin{array}{c}8 \\
(15 \%)\end{array}$ & $\begin{array}{c}235 \\
(14 \%)\end{array}$ \\
\hline \multicolumn{2}{|c|}{ Screening Stage Response Rate ${ }^{a}$} & $43 \%$ & $41 \%$ & $41 \%$ & $15 \%$ & $28 \%$ & $52 \%$ & $34 \%$ \\
\hline \multirow{3}{*}{$\begin{array}{l}\text { Nonresponding } \\
\text { Persons }\end{array}$} & $\begin{array}{l}\text { Refusals after } \\
\text { screening }\end{array}$ & 4 & 5 & 10 & 4 & 12 & 2 & 37 \\
\hline & Other & 27 & 10 & 30 & 6 & 13 & 6 & 92 \\
\hline & Category Total & $\begin{array}{c}31 \\
(7 \%)\end{array}$ & $\begin{array}{c}15 \\
(9 \%)\end{array}$ & $\begin{array}{c}40 \\
(11 \%)\end{array}$ & $\begin{array}{c}10 \\
(3 \%)\end{array}$ & $\begin{array}{c}25 \\
(7 \%)\end{array}$ & $\begin{array}{c}8 \\
(15 \%)\end{array}$ & $\begin{array}{c}129 \\
(8 \%)\end{array}$ \\
\hline Recruits & Category Total & $\begin{array}{c}47 \\
(11 \%)\end{array}$ & $\begin{array}{c}16 \\
(10 \%)\end{array}$ & $\begin{array}{c}35 \\
(10 \%)\end{array}$ & $\begin{array}{c}18 \\
(6 \%)\end{array}$ & $\begin{array}{c}35 \\
(9 \%)\end{array}$ & $\begin{array}{c}11 \\
(20 \%)\end{array}$ & $\begin{array}{c}162 \\
(10 \%)\end{array}$ \\
\hline \multicolumn{2}{|c|}{ Totals-All Categories } & 427 & 158 & 363 & 324 & 375 & 55 & 1,702 \\
\hline \multicolumn{2}{|c|}{ Recruitment Stage Response Rate ${ }^{b}$} & $60 \%$ & $52 \%$ & $47 \%$ & $64 \%$ & $58 \%$ & $\mathbf{5 8 \%}$ & $56 \%$ \\
\hline \multicolumn{2}{|c|}{ Overall Recruitment Response Ratec } & $26 \%$ & $21 \%$ & $19 \%$ & $10 \%$ & $16 \%$ & $30 \%$ & $19 \%$ \\
\hline
\end{tabular}

DEARS = Detroit Exposure and Aerosol Research Study; EMA = enumeraion monitoring area.

a Screening Stage Response Rate $=$ (Ineligible Households + Nonresponding Persons + Recruits) $\div$

(Nonresponding Households + Ineligible Households + Nonresponding Persons + Recruits)

b Recruitment Stage Response Rate $=$ Recruits $\div$ (Nonresponding Persons + Recruits)

c Overall Recruitment Response Rate $=$ Screening Stage Response Rate x Recruitment Stage Response Rate 
Table 3 presents data on the same categories and subcategories as Table 2, but by season rather than EMA. Only Seasons 1, 3, and 5 are presented in Table 3 because these summer seasons required a new cohort of study participants and thus the greatest recruitment effort. A difference between Season 1 and
Seasons 3 and 5 is the percentage of nonresponding households, which rose from 38 percent (Season 1) to 73 percent (Season 3 ) and 63 percent (Season 5). The numbers for the "no one at residence" and "refused screener" categories increased considerably.

Table 3. Cohort recruitment details for the DEARS, by summer season

\begin{tabular}{|c|c|c|c|c|c|}
\hline Category & Subcategory & Season 1 & Season 3 & Season 5 & Total \\
\hline \multirow{5}{*}{$\begin{array}{l}\text { Ineligible } \\
\text { Residences }\end{array}$} & Not a residential address & 4 & 6 & 12 & 22 \\
\hline & Unable to locate address & 20 & 1 & 6 & 27 \\
\hline & Vacant & 16 & 21 & 39 & 76 \\
\hline & Multifamily dwelling & 41 & 2 & 0 & 43 \\
\hline & Category Total & $\begin{array}{c}81 \\
(15 \%)\end{array}$ & $\begin{array}{c}30 \\
(5 \%)\end{array}$ & $\begin{array}{c}57 \\
(11 \%)\end{array}$ & $\begin{array}{c}168 \\
(10 \%)\end{array}$ \\
\hline \multirow{4}{*}{$\begin{array}{l}\text { Nonresponding } \\
\text { Households }\end{array}$} & No one at residence & 62 & 291 & 140 & 493 \\
\hline & Access denied & 2 & 6 & 13 & 21 \\
\hline & Refused screener & 132 & 189 & 173 & 494 \\
\hline & Category Total & $\begin{array}{c}196 \\
(38 \%)\end{array}$ & $\begin{array}{c}486 \\
(73 \%)\end{array}$ & $\begin{array}{c}326 \\
(63 \%)\end{array}$ & $\begin{array}{l}1,008 \\
(59 \%)\end{array}$ \\
\hline \multirow{4}{*}{$\begin{array}{l}\text { Ineligible } \\
\text { Households }\end{array}$} & Smoker in household & 91 & 52 & 37 & 180 \\
\hline & Language barrier; other & 32 & 2 & 2 & 36 \\
\hline & Physically/mentally incapable & 7 & 3 & 9 & 19 \\
\hline & Category Total & $\begin{array}{c}13 \\
(25 \%)\end{array}$ & $\begin{array}{c}5 \\
(9 \%)\end{array}$ & $\begin{array}{c}4 \\
(9 \%)\end{array}$ & $\begin{array}{c}23 \\
(14 \%) \\
\end{array}$ \\
\hline \multicolumn{2}{|c|}{ Screening Stage Response Rate } & $55 \%$ & $24 \%$ & $29 \%$ & $34 \%$ \\
\hline \multirow{3}{*}{$\begin{array}{l}\text { Nonresponding } \\
\text { Persons }\end{array}$} & Refusals after screening & 16 & 21 & 0 & 37 \\
\hline & Otherb & 38 & 18 & 36 & 92 \\
\hline & Category Total & $\begin{array}{c}54 \\
(10 \%)\end{array}$ & $\begin{array}{c}39 \\
(6 \%)\end{array}$ & $\begin{array}{c}36 \\
(7 \%)\end{array}$ & $\begin{array}{r}129 \\
(8 \%)\end{array}$ \\
\hline Recruits & Category Total & $\begin{array}{c}57 \\
(11 \%) \\
\end{array}$ & $\begin{array}{c}54 \\
(8 \%)\end{array}$ & $\begin{array}{c}51 \\
(10 \%)\end{array}$ & $\begin{array}{c}162 \\
(10 \%)\end{array}$ \\
\hline \multicolumn{2}{|c|}{ Totals-All Categories } & 518 & 666 & 518 & 1,702 \\
\hline \multicolumn{2}{|c|}{ Recruitment Stage Response Ratec } & $51 \%$ & $58 \%$ & $59 \%$ & $56 \%$ \\
\hline \multicolumn{2}{|c|}{ Overall Recruitment Response Rated } & $28 \%$ & $14 \%$ & $17 \%$ & $19 \%$ \\
\hline
\end{tabular}

DEARS = Detroit Exposure and Aerosol Research Study.

a Screening Stage Response Rate $=$ (Ineligible Households + Nonresponding Persons + Recruits) $\div$ (households + Nonresponding Persons + Recruits)

b Respondents who expressed interest but could not be recontacted or could not participate for personal or work reasons.

c Recruitment Stage Response Rate $=$ Recruits $\div$ (Nonresponding Persons + Recruits)

d Overall Recruitment Response Rate $=$ Screening Stage Response Rate $x$ Recruitment Stage Response Rate

Note: Summer seasons appear in this table because each summer a new cohort of study participants was recruited. During the winter season we tried to re-enroll these participants. 


\section{Enrollment}

Table 4 provides detail about the number of participants enrolled in each season and by EMA. The New Participants column refers to individuals enrolled for the first time during that season (e.g., 40 new participants enrolled in Season 3). Each summer, corresponding to Seasons 1, 3, and 5, we enrolled a new cohort of participants. Summer participants were also asked to participate in the winter season. The number of participants who enrolled in both the summer and winter seasons (two seasons) appears in the Participated in 2 Seasons column (e.g., 31 participants enrolled in Seasons 3 and 4). The Percentage Retained column is the percentage of summer season participants also enrolled in the subsequent winter season (e.g., 71 percent of the Season 1 participants were enrolled in Season 2).
As described earlier, participants from all of the EMAs were not sampled each season (e.g., no participants from EMA 5 were enrolled in Seasons 1 and 2). Season 6 was truncated because of insufficient financial resources; however, we still considered it fully successful with 28 participants because each week's environmental monitoring schedule included a full complement of participants.

The demographic characteristics of the DEARS participants are shown in Table 5. A large proportion of the study population is female (77 percent).

Many study participants reported that they had not worked in the past week (67 percent). Aside from EMA 7, which was primarily a white, middle-class community, the participants enrolled in the lower income EMAs are more likely to be non-white and almost one-third are Hispanic.

Table 4. DEARS participant enrollment summary, by EMA and season

\begin{tabular}{|c|c|c|c|c|c|c|c|c|c|c|}
\hline Season & EMA 1 & EMA 3 & EMA 4 & EMA 5 & EMA 6 & EMA 7 & Total & $\begin{array}{c}\text { New } \\
\text { Participants }\end{array}$ & $\begin{array}{l}\text { Participated } \\
\text { in } 2 \text { Seasons }\end{array}$ & $\begin{array}{c}\text { Percentage } \\
\text { Retained }\end{array}$ \\
\hline Season 1 & 8 & 8 & 7 & - & 9 & 6 & 38 & 38 & $\mathrm{~N} / \mathrm{A}$ & $\mathrm{N} / \mathrm{A}$ \\
\hline Season 2 & 6 & 11 & 5 & - & 7 & 7 & 36 & 9 & 27 & 71 \\
\hline Season 3 & 9 & 5 & 8 & 8 & 10 & - & 40 & 40 & $\mathrm{~N} / \mathrm{A}$ & $\mathrm{N} / \mathrm{A}$ \\
\hline Season 4 & 9 & 5 & 8 & 8 & 10 & - & 40 & 9 & 31 & 78 \\
\hline Season 5 & 9 & - & 11 & 9 & 11 & - & 40 & 40 & $\mathrm{~N} / \mathrm{A}$ & $\mathrm{N} / \mathrm{A}$ \\
\hline Season 6 & 8 & - & 8 & 5 & 7 & - & 28 & $\mathrm{~N} / \mathrm{A}$ & 28 & 70 \\
\hline Totals & 49 & 29 & 47 & 30 & 54 & 13 & 222 & 136 & 86 & 73 \\
\hline
\end{tabular}

DEARS $=$ Detroit Exposure and Aerosol Research Study; EMA = enumeration monitoring area.

- = no enrollment in the EMA during that season.

Note: EMA 5 was not included in the study design until Season 3. EMA 7 was only used for outdoor measurements during Seasons 3 through 6 . Similarly, EMA 3 was also used for outdoor only measurements in Seasons 5 and 6.

Table 5. Demographic characteristics of the enrolled cohort in the DEARS over six seasons

\begin{tabular}{|c|c|c|c|}
\hline \multicolumn{4}{|l|}{ Characteristic } \\
\hline Gender & $23 \%$ male & $77 \%$ female & \\
\hline Ethnicity & 29\% Hispanic & $71 \%$ non-Hispanic & \\
\hline Race & $28 \%$ white & 51\% African American & $21 \%$ other race \\
\hline Age & Range: 18 to 79 years & Median: 41 years & \\
\hline Worked in past week & $33 \%$ worked & $67 \%$ did not work & \\
\hline Primary language & 13\% Spanish & 87\% English & \\
\hline
\end{tabular}

DEARS $=$ Detroit Exposure and Aerosol Research Study. 


\section{Retention}

Overall, 73 percent of summer season participants enrolled again in the winter season. Table 6 summarizes the characteristics of the participants who withdrew from the DEARS after one season of participation. A total of 32 participants withdrew, roughly equally distributed across the seasons. EMAs 4 and 6 had the most participant withdrawals. EMAs 3 and 7 had the fewest withdrawals, although participants were not recruited for all seasons in these EMAs. When classified by race, African American participants withdrew more frequently than white participants ( 31 percent vs. 23 percent), including participants of Hispanic ethnicity (22 percent). Further, male participants withdrew more frequently than female participants ( 33 percent vs. 25 percent).

\section{Protocol Compliance}

"Waking compliance" is a term used to define the number of hours the vest was worn during the waking hours of the day. The DEARS staff used 17 hours as the nominal number of waking hours. The number of hours the vest was worn during the day was divided by the total number of waking hours and the result was a percentage. The average waking compliance across all of the DEARS seasons was 66 percent (P. Lawless, personal communication, 2008).

Table 7 provides information about the protocol violations that occurred in Seasons 5 and 6. Three vest protocol violations and two tobacco smoke violations occurred in Season 5. Although the number of participants enrolled decreased from 40 to 28 from Season 5 to Season 6, the number of violations doubled.

\begin{tabular}{|c|c|c|c|c|c|c|c|c|c|c|c|}
\hline \multirow[b]{2}{*}{ Season } & \multirow[b]{2}{*}{ Totals } & \multicolumn{6}{|c|}{ EMA } & \multicolumn{2}{|c|}{ Race/Ethnicity } & \multicolumn{2}{|c|}{ Gender } \\
\hline & & 1 & 3 & 4 & 5 & 6 & 7 & $\begin{array}{c}\text { White } \\
\text { (Hispanic) }\end{array}$ & $\begin{array}{l}\text { African } \\
\text { American }\end{array}$ & Male & Female \\
\hline Seasons 1 and 2 & 11 & 2 & 0 & 5 & $\mathrm{~N} / \mathrm{A}$ & 4 & 0 & $2(1)$ & 9 & 7 & 4 \\
\hline Seasons 3 and 4 & 9 & 4 & 0 & 1 & 1 & 3 & $\mathrm{~N} / \mathrm{A}$ & $6(3)$ & 3 & 0 & 9 \\
\hline Seasons 5 and 6 & 12 & 1 & $\mathrm{~N} / \mathrm{A}$ & 3 & 4 & 4 & $\mathrm{~N} / \mathrm{A}$ & $6(4)$ & 6 & 2 & 10 \\
\hline $\begin{array}{l}\text { Total withdrawals } \\
\text { (\% of enrollment) }\end{array}$ & $\begin{array}{c}32 \\
(27 \%)\end{array}$ & $\begin{array}{c}7 \\
(27 \%)\end{array}$ & $\begin{array}{c}0 \\
(0 \%)\end{array}$ & $\begin{array}{c}9 \\
(35 \%)\end{array}$ & $\begin{array}{c}5 \\
(29 \%)\end{array}$ & $\begin{array}{c}11 \\
(37 \%)\end{array}$ & $\begin{array}{c}0 \\
(0 \%)\end{array}$ & $\begin{array}{c}14(8) \\
(23 \%, 22 \%)\end{array}$ & $\begin{array}{c}18 \\
(31 \%)\end{array}$ & $\begin{array}{c}9 \\
(33 \%)\end{array}$ & $\begin{array}{c}23 \\
(25 \%)\end{array}$ \\
\hline
\end{tabular}

DEARS = Detroit Exposure and Aerosol Research Study; EMA = enumeration monitoring area

\section{Table 7. DEARS sample collection protocol violations in Seasons 5 and 6}

\begin{tabular}{|c|c|c|c|}
\hline Season & Total Number of Participants & Vest Protocol Violations & Tobacco Smoke Violations \\
\hline Season 5 & 40 & 3 & 2 \\
\hline Season 6 & 28 & $7^{a}$ & $3^{a}$ \\
\hline
\end{tabular}

DEARS $=$ Detroit Exposure and Aerosol Research Study

a One participant violated both the vest and tobacco smoke protocols. 


\section{Discussion}

\section{Recruitment}

Because the DEARS recruiters did not visit residences more than three times, the response rates may not be comparable with those from other studies, such as the National Human Exposure Assessment Survey, ${ }^{20}$ a major population-based exposure study. However, it is not unreasonable to assume that response rates would improve if the number of nonresponding households was reduced, but a significant effort and substantial resources would be necessary to achieve better response rates.

The DEARS response rates were considered sufficient because the DEARS analyses are model based, and the estimation of demographic characteristics of the DEARS population was not a study goal. Estimates of model relationships would be biased only if the relationships were different for respondents and nonrespondents. Hence, the likelihood of nonresponse bias is less for model-based relationships than for estimates of demographic characteristics, such as population means and totals.

\section{Enrollment}

Enrollment in the DEARS was considered a success both by season and across the EMAs because enrollment goals were achieved in nearly every season. Additionally, the researchers enrolled enough individuals in each EMA to meet the needs of the statistical design.

Not all individuals recruited (162), however, were enrolled as participants in the DEARS (136). The additional individuals recruited, called alternates, were necessary because some of the individuals recruited could not participate in the study. The alternates were informed that they might not be able to participate. Most of the time, the individual recruited was engaged and willing to participate in the DEARS; however, some decided not to sign the consent form to enroll after giving verbal consent to the recruiter.

Some of the individuals recruited who decided not to participate (dropouts) had to be replaced at the last minute. Nearly every week of the 7-week summer season, an individual scheduled for recruitment opted out of the study before or during the first home visit. Often, another household member (e.g., spouse or head of household) influenced the enrollment decision; in some cases, we could not reach the recruited individual. Fortunately, alternates who were recruited from the same EMA were available to fill the sampling schedule.

\section{Retention}

Overall, retention was also considered successful because the large majority of the DEARS participants (73 percent) took part in both the summer and winter seasons. Some of the summer participants could not participate in the winter season because of their work schedules or family commitments. Other participants moved out of the study area and became ineligible for the study.

The letter and calendar sent to participants prior to the winter season proved to be an excellent tool. This also lessened the need for in-person recruiter followup because the majority of the participants were already scheduled.

Retention was lower among African Americans and males. African American enrollees typically did not participate in a second season because of the mobility of the cohort; they were more likely to move out of the study area and thus became ineligible to participate in the second season. No definitive information was gathered to explain the lower retention rates for males. Anecdotally, however, male participants found compliance with study protocols too burdensome or lost interest in the study objectives. Individuals who were less interested in the study and did not want to participate in a second season were also less compliant.

\section{Protocol Compliance}

One change instituted during the last year of the study allowed for the use of graduated burden compensation for participants who did not or could not fully participate. Participants received a compensation table in the consent form that clearly stated the compensation would be reduced in the following circumstances: (a) the vest was not worn as required to meet the study protocol during waking 
hours, (b) smoking was allowed in the residence during the study period, or (c) no one was home or available to meet the technicians for a scheduled home visit.

Participants violating the nonsmoking household requirement would have the personal and the indoor sampling incentives reduced or eliminated. This change in protocol allowed reductions from the full $\$ 300$ incentive to be dropped in stages to as low as $\$ 155$ for lack of full protocol compliance.

Unfortunately, compliance was lower in Season 6 (10 violations) than in Season 5 (5 violations). Some of the participants were certainly less motivated and complained about wearing the vest, or they experienced personal issues that precluded their full participation. Other participants allowed smoking in their homes; consequently, the personal and indoor sampling had to be discontinued.

Undoubtedly, the reduced incentive plan prompted better protocol compliance among some participants; however, we could not assess its value directly because personal sampling participation was terminated after a given participant ignored the first warning from the technicians. Investigators conducting future cohort studies might consider holding exit interviews addressing this issue to better understand the net value (advantages and disadvantages) of a reduced incentive plan. The closer tracking of participant compliance and the termination of personal sampling minimized the costs associated with analyzing exposure samples that were inadequate. Thus, the samples would then have been voided.

\section{Summary}

Although the DEARS met the recruitment goal of 40 study participants per study year (summer and winter seasons), the recruitment and retention activities required extensive and creative efforts. Sending recruiters to 1,700 households to obtain 136 enrollees was both time consuming and resource intensive. However, the DEARS techniques worked and helped avoid problems caused by nonrespondents, low interest in the study, and dropouts.
Community-based participatory research facilitated the start-up of and recruitment for the DEARS, as it has for other studies in Detroit and elsewhere. These local organizations and community members provided guidance and suggestions about the study design, such as how a particular population should be approached (e.g., African Americans in low socioeconomic status areas of Detroit or immigrant farm workers in California). They also portray the study in a positive light, which builds trust in the community. Although these organizations may not have the skills and expertise of a research organization or an academic institution, they provide valuable local insight and support. ${ }^{14,21}$

Table 8 summarizes these lessons learned, including several recruitment and retention characteristics of the DEARS that were successful or unsuccessful and the reasons for this assessment. Many aspects of the DEARS recruitment effort can be judged as successful, including enabling communication 24 hours a day, 7 days a week, scheduling home visits, enrolling participants in the targeted areas, and ensuring the timeliness of the recruitment effort.

Low response rates and dropouts presented problems at times; however, by putting in additional time recruiting and filling the schedule with alternates, we were able to alleviate major problems. Because the DEARS sampling schedule could not be changed easily if a participant dropped out, recruiters acted quickly to contact an alternate in the same EMA and fill the time slot for the week's schedule. Unfortunately, a few of the DEARS participants did not wear the vest as requested and their personal exposure data were not usable. Attendance at participant meetings was low, and the DEARS staff assumed that the problem was participants' lack of interest or the inability to find transportation to meetings. Letters and telephone reminders did not increase participation at the meetings. 


\section{Table 8. Characteristics of successful and unsuccessful DEARS recruitment and retention efforts}

\begin{tabular}{|c|c|}
\hline Characteristic & Reasons for Successful Efforts \\
\hline Staffing & $\begin{array}{l}\text { Dependable and experienced } \\
\text { recruiters who had conducted similar } \\
\text { recruitment/outreach efforts in the } \\
\text { same urban areas. }\end{array}$ \\
\hline $\begin{array}{l}\text { Cultural and ethnic } \\
\text { sensitivity }\end{array}$ & $\begin{array}{l}\text { Insight from meetings with } \\
\text { community action groups; recruiters } \\
\text { of same race/ethnicity as targeted } \\
\text { population. }\end{array}$ \\
\hline $\begin{array}{l}\text { Communication between } \\
\text { recruiter and field team }\end{array}$ & Cell phones, frequent communication. \\
\hline $\begin{array}{l}\text { Enrolled enough } \\
\text { participants in the targeted } \\
\text { areas }\end{array}$ & $\begin{array}{l}\text { Good management, staffing, } \\
\text { coordination, successful recruitment } \\
\text { efforts, over-recruitment. }\end{array}$ \\
\hline Scheduling home visits & $\begin{array}{l}\text { Accommodated participant's personal } \\
\text { and work schedules. }\end{array}$ \\
\hline Timeliness & $\begin{array}{l}\text { All recruitment and retention } \\
\text { quotas achieved in time to meet the } \\
\text { unforgiving environmental sampling } \\
\text { schedule; good management and } \\
\text { coordination of field efforts. }\end{array}$ \\
\hline Dropouts & $\begin{array}{l}\text { Respondent changed his or her mind } \\
\text { or was nonresponsive; alternate } \\
\text { contacted immediately to fill the } \\
\text { schedule. }\end{array}$ \\
\hline $\begin{array}{l}\text { Translated study materials; } \\
\text { provided a translator for } \\
\text { home visits }\end{array}$ & $\begin{array}{l}\text { All study materials available in } \\
\text { Spanish and English; translator } \\
\text { accompanied field team for Spanish- } \\
\text { speaking participants. }\end{array}$ \\
\hline Retention & $\begin{array}{l}\text { Maintained communication between } \\
\text { seasons, allowed participants to self- } \\
\text { schedule in winter. }\end{array}$ \\
\hline Characteristic & Reasons for Unsuccessful Efforts \\
\hline Low response rates & $\begin{array}{l}\text { Refusals, perceived burden, "no } \\
\text { one home," not enough visits to the } \\
\text { sample homes. }\end{array}$ \\
\hline $\begin{array}{l}\text { Low attendance }(<20 \%) \\
\text { at the between-season } \\
\text { meetings }\end{array}$ & $\begin{array}{l}\text { Lack of interest, unavailable, or lack of } \\
\text { transportation the day of meeting. }\end{array}$ \\
\hline Protocol compliance & $\begin{array}{l}\text { Smoking allowed in the home; vest } \\
\text { was not worn during all waking hours. }\end{array}$ \\
\hline
\end{tabular}

DEARS $=$ Detroit Exposure and Aerosol Research Study.

\section{Conclusion}

This report summarizes multiple aspects of recruitment and retention related to personal exposure studies that rarely appear in the literature. In particular, it describes the challenges of participant recruitment and retention for a longitudinal exposure study in low-income and minority urban areas. If researchers are aware of these challenges and have the necessary time frame and resources to address them, most of them can be alleviated.

Based on our experience with the DEARS, the box below lists some approaches that may help improve recruitment and retention in low socioeconomic status populations. These suggestions should be viewed as general guidelines that were applied successfully during the DEARS. It is likely that they can be incorporated into most recruitment and retention efforts with minorities in urban areas.

\section{Tools for recruitment and retention success in longitudinal research studies}

- Include input from community groups and leaders during study planning phase.

- Hire local staff of the same ethnicity as the prospective respondents.

- Depending on the population, develop high-quality recruitment and data collection materials in English and Spanish.

- Hire at least one bilingual recruiter who can also accompany field staff for translation purposes.

- Adhere closely to Institutional Review Board (IRB) requirements.

- Visit or call potential participants on different days of the week and at different times of the day.

- Build a caring and trusting relationship with participants.

- Minimize the time between recruitment and sampling.

- Give respondents as many scheduling options as possible.

- Simplify study materials and procedures.

- Monitor recruiter efficiency and success.

- Share as much information as possible about the participants recruited with the field teams who visit the homes (e.g., dog tied up in backyard).

- Recruit more participants than may be necessary, and inform the additional participants that they may be "alternates."

- Minimize problems from last-minute dropouts by having alternates.

- Remind participants about their home visits 1 or 2 days in advance.

- Use cash, if possible, for incentive compensation.

- Modify/decrease compensation if participant compliance is unacceptable. 
First, careful planning with local community groups, preparation of high-quality study materials, hiring and training of experienced recruiters from the local area (including bilingual recruiters, if needed), and approval by IRBs are essential steps in the first stage of the study.

Second, recruitment and enrollment efforts will benefit from establishing good relationships with the study participants, accommodating their work or personal schedules, maintaining good communication between the recruiters and field teams, and scheduling participants 2 weeks in advance. Other preparations include over-recruitment to have a pool of alternates; use of sufficient, but not coercive, incentives (cash if possible); telephone reminders to participants 2 days in advance of their first home visit; and a method to monitor protocol compliance.

Finally, longitudinal studies like the DEARS require retention efforts, such as maintaining a good relationship with participants, mailing scheduling letters with calendars, and conducting follow-up telephone reminders.

\section{References}

1. Blumenthal DS, Sung J, Coates R, Williams J, Liff J. Recruitment and retention of subjects for a longitudinal cancer prevention study in an inner-city black community. Health Serv Res 1995;30(1 Pt 2):197-205.

2. Eskenazi B, Gladstone EA, Berkowitz GS, Drew CH, Faustman EM, Holland NT, et al. Methodologic and logistic issues in conducting longitudinal birth cohort studies: lessons learned from the Centers for Children's Environmental Health and Disease Prevention Research. Environ Health Perspect 2005;113(10):1419-29.

3. Sexton K, Adgate JL, Church TR, Greaves IA, Ramachandran G, Fredrickson AL, et al. Recruitment, retention, and compliance results from a probability study of children's environmental health in economically disadvantaged neighborhoods. Environ Health Perspect 2003;111(5):731-36.

4. Adderley-Kelly B, Green PM. Strategies for successful conduct of research with low-income African American populations. Nurs Outlook 2005;53(3):147-52.

5. Krieger J, Takaro T, Allen C, Song L, Weaver $\mathrm{M}$, Chai S, et al. The Seattle-King County Healthy Homes Project: implementation of a comprehensive approach to improving indoor air quality for low-income children with asthma. Environ Health Perspect 2002;11(Suppl 2): S311-22.
6. Groves RM. Survey errors and survey costs. Hoboken, NJ: John Wiley \& Sons; 2004.

7. Galea S, Tracy M. Participation rates in epidemiological studies. Ann Epidemiol 2007;17:643-53.

8. Dugbatey K, Croskey V, Evans RG, Narayan G, Osamudiamen OE. Lessons from a primaryprevention program for lead poisoning among inner-city children. J Environ Health 2005;68(5):15-20, 26.

9. Chuang JC, Callahan PJ, Lyu CW, Wilson NK. Polycyclic aromatic hydrocarbon exposures of children in low-income families. J Expo Anal Environ Epidemiol 1999;9(2):85-98.

10. Weisel CP, Zhang J, Turpin BJ, Morandi MT, Colome S, Stock TH, et al. Relationship of Indoor, Outdoor and Personal Air (RIOPA) study: study design, methods and quality assurance/control results. J Expo Anal Environ Epidemiol 2005;15(2):123-37.

11. Alvarez RA, Vasquez E, Mayorga CC, Feaster DJ, Mitrani VB. Increasing minority research participation through community organization outreach. West J Nurs Res 2006;28(5):541-60.

12. Lewis TC, Robins TG, Joseph CL, Parker EA, Israel BA, Rowe Z, et al. Identification of gaps in the diagnosis and treatment of childhood asthma using a community-based participatory research approach. J Urban Health 2004;1(3):472-88. 
13. Parker EA, Israel BA, Williams M, BrakefieldCaldwell W, Lewis TC, Robins T, et al. Community action against asthma: examining the partnership process of a community-based participatory research project. J Gen Intern Med 2003;18(7):558-67.

14. Lewis TC, Robins TG, Dvonch JT, Keeler GJ, Yip FY, et al. Air pollution-associated changes in lung function among asthmatic children in Detroit. Environ Health Perspect 2005;113(8):1068-1075.

15. Williams R. EPA's Detroit Exposure and Aerosol Research Study. In: EPA Research Highlights, AWMA Environmental Manager; October 2005. p. 43.

16. Williams R, Rea A, Vette A, Croghan C, Whitaker D, Stevens $\mathrm{C}$, et al. The design and field implementation of the Detroit Exposure and Aerosol Research Study. J Exp Sci Env Epi. 2009;19:643-59.

17. American Association for Public Opinion Research (AAPOR) [Internet]. Standard definitions: final dispositions of case codes and outcome rates for surveys. 2006. Available from: http://www.aapor.com
18. Pellizzari E, Lioy P, Quackenboss J, Whitmore R, Clayton A, Freeman N, Waldman J, Thomas $\mathrm{K}$, Rodes C, Wilcosky T. Population-based exposure measurements in EPA Region 5: a Phase I field study in support of the National Human Exposure Assessment Survey. J. Environ. Epi 1995;5(3):327-358.

19. Lawless PA, Rodes CE, Ensor DS. Multiwavelength absorbance of filter deposits for determination of environmental tobacco smoke and black carbon. Atmos Env 2004;38:3373-83.

20. Whitmore RW, Byron MZ, Clayton CA, Thomas KW, Zelon HS, Pellizzari ED, et al. Sampling design, response rates, and analysis weights for the National Human Exposure Assessment Survey (NHEXAS) in EPA region 5. J Expo Anal Environ Epidemiol 1999;9(5):369-80.

21. Eskanazi B, Bradman A, Gladstone EA, Jaramillo S, Birch K, Holland N. CHAMACOS, a longitudinal birth cohort study: lessons from the fields. J Children's Health 2003;1(1):3-27. 



\section{Acknowledgments}

The US Environmental Protection Agency, through its Office of Research and Development, partially funded the research described here through Contract 68-D-99-012 (RTI International), EP-D-04-065 and EP-D-68-00-206 (Alion Science and Technology), EP-D-04-068 (Battelle Columbus Laboratories), and 4D-5653-NAEX (University of Michigan). Although this work was reviewed by EPA and approved for publication, it may not necessarily reflect official Agency policy. Mention of trade names or commercial products does not constitute an endorsement or recommendation for use.

We would like to thank Andrew Dart, Jeremy Seagraves, Jeff Portzer, and the other field technicians and office managers for tirelessly coordinating with the recruitment staff. We also would like to thank Justine Allpress for producing maps of the areas and Dhuly Chowdhury for her assistance with the statistics. We are grateful to Farid Shamo, Kathy Edgren, Wilma Brakefield-Caldwell, Maria Salinas, the Community Action Against Asthma (CAAA), the Arab Community Center for Economic and Social Services (ACCESS), and the recruiters for their hard work and persistence to meet recruitment goals. And we would like to thank Ann Chevalier and Mary Ann Heindorf of the Michigan Department of Environmental Quality for providing accommodations for participant meetings. 
RTI International is an independent, nonprofit research organization dedicated to improving the human condition by turning knowledge into practice. RTI offers innovative research and technical solutions to governments and businesses worldwide in the areas of health and pharmaceuticals, education and training, surveys and statistics, advanced technology, international development, economic and social policy, energy and the environment, and laboratory and chemistry services.

The RTI Press complements traditional publication outlets by providing another way for RTI researchers to disseminate the knowledge they generate. This PDF document is offered as a public service of RTI International. More information about RTI Press can be found at www.rti.org/rtipress. 